\title{
Molybdenum Trioxide Microrods synthesized with Corn Straw as Biological Templates and its Electrochemical Performance in Aqueous Battery
}

\author{
Jianzhi Sun ${ }^{1 *}$, Yan Dong ${ }^{1}$, Xinfang Wang ${ }^{1}$, Chunyan Kong ${ }^{1}$, Jinming Hong ${ }^{1}$, Chunhui $\mathrm{Li}^{2}$ \\ ${ }^{1}$ College of Chemistry and Chemical Engineering, Dezhou University, Shandong Dezhou, 253023, P. R. China \\ ${ }^{2}$ Experiment Management Centre, Dezhou University, Shandong Dezhou, 253023, P. R. China
}

Corresponding Author Email: jianzhisun@163.com

\begin{abstract}
In this paper, $\mathrm{MoO}_{3}$ microrods was prepared using corn straw as biological template via roasting process. The components and crystal characterization of the material were investigated via X-ray diffraction(XRD), scanning electron microscopy( SEM), and the electrochemistry property and mechanism was studied. The results show that the $\mathrm{MoO}_{3}$ material synthesized by template method is Orthorhombic structures. And the $\mathrm{MoO}_{3}$ particles were submicron and micron rods with uniform distribution and a smooth surface. $\mathrm{MoO}_{3}$ microrods had an average diameter that ranged from 1 to $2 \mu \mathrm{m}$. The result indicated that the $\mathrm{MoO}_{3}$ as the new negative of aluminum battery delivers a higher discharge capacity of $190 \mathrm{mAh} / \mathrm{g}$ at a scanning rate of $1 \mathrm{mv} / \mathrm{s}$, which showing good capacity and cycling performance.
\end{abstract}

Keywords: Biological Template, Corn Straw, Rechargeable aqueous battery, Aluminium-ion battery, $\mathrm{MoO}_{3}$ Received: 05-February-2021, Accepted: 07-April-2021, https://doi.org/10.14447/jnmes.v24i2.a03

\section{INTRODUCTION}

With growing concern about the environment, climate change and a sustainable energy supply, studies have been focused on the development of green energy storage systems with high volumetric energy density, low price and improved safety. In order to solve discontinuous and instable problems of renewable electricity (such as solar arrays and wind farms), energy storage systems can be used. The new advanced batteries are needed to have not only high energy density, but also good safety and affordable electric storage systems that enables better use of the intermittent renewable energy sources [1-4]. Because of superior performance in various electrochemical aspects, Li-ion batteries are often viewed as an energy storage device. However, limited resource and the high price of lithium salt restrict its application in this area.

Orthorhombic molybdenum trioxide $\left(\alpha-\mathrm{MoO}_{3}\right)$ has been extensively investigated as a key material for fundamental research and technological applications in photocatalyst, solar cells, and electrochemical storage. The most important structural characteristic of $\alpha-\mathrm{MoO}_{3}$ is its structural anisotropy, which can be considered as a layered structure parallel to (010). Each layer is composed of two sub-layers, each of which is formed by corner-sharing octahedral along [001] and [100]; the two sub-layers stack together by sharing the edges of the octahedra along [001]. An alternate stack of these layered sheets along [010] would lead to the formation of $\alpha-\mathrm{MoO}_{3}$, where a van der Waals interaction would be the major binding force between the piled sheets [5-8]. However, there are few literature on the report of its electrochemical performance in aqueous rechargeable Aluminum-ion battery.

Biological Templates have attracted considerable attention for the syntheses of inorganic materials in the recent several years [9], because they are generally performed under mild conditions, it is energy-conserving, green, and has little requirement for equipment. Moreover, most natural templates and building blocks can be harvested in large amounts at low costs. Thus biomorphic assembly is cheap compared with conventional assembly methods to form nanostructures.

Corn is one of major crops planted in China. There are about 0.2 billion tons of corn stalk produced annually. As agricultural waste in the world, the corn stalk has been widely used because of its many advantages, including easy preparation and low cost economical [10].

Aqueous aluminum ion batteries are one of the promising technologies for the green energy storage, which demonstrate attractive features of large theoretical capacity $(2980 \mathrm{mAh} / \mathrm{g}$ and $8046 \mathrm{mAh} / \mathrm{cm}^{3}$ ), reversible plating/stripping of $\mathrm{Al}$, high ionic conductivity, non-toxic electrolyte, high safety, environmental friendliness, low cost and facile manufacturing process[11-14]. Molybdenum trioxide $\left(\mathrm{MoO}_{3}\right)$, as a potential negative electrode material has a lot of advantages, such as high electrochemical activity, low cost, and environmentally friendly nature $[15,16]$. However, there are few literature on the report of its electrochemical performance in aqueous rechargeable Aluminum-ion battery. In this study, $\mathrm{MoO}_{3}$ was prepared by the solid-phase method and biological template method and its electrochemical behavior in $1.0 \mathrm{~mol} / \mathrm{L} \mathrm{AlCl}_{3}$ aqueous solution is discussed.

\section{EXPERIMENTAL}

\subsection{Material preparation}

The $\mathrm{MoO}_{3}$ was synthesized via solid-phase method and biological template method. $\mathrm{MoO}_{3}$ ( I ) was prepared by solid state reaction. Ammonium molybdate $\left(\left(\mathrm{NH}_{4}\right)_{6} \mathrm{Mo}_{7} \mathrm{O}_{24} \cdot 4 \mathrm{H}_{2} \mathrm{O}\right)$ was placed in a tubular furnace with the heating temperature from 20 to $450^{\circ} \mathrm{C}$ at $5^{\circ} \mathrm{C} / \mathrm{min}$ in air and incubated at $450^{\circ} \mathrm{C}$ for a further two hours.

The $\mathrm{MoO}_{3}$ (II) was synthesized by biological template method. The corn stalk was washed thoroughly with water to remove the adhering soil and dust. Then, in order to improve adsorption ability of corn straw, they were cut and immersed 
in $5 \%$ ammonia solution at room temperature for $8 \mathrm{~h}$ to eliminate hemicelluloses, lignin and some other components. The corn stalk was washed to the neutral with distilled water and further dried in an oven at $60^{\circ} \mathrm{C}$ until they were completely dehydrated before are used. Then the dehydrated corn stalk was simply dipped into $0.5 \mathrm{~mol} / \mathrm{L}$ Ammonium molybdate solution for $24 \mathrm{~h}$. The sample was washed with distilled three times and dried in an oven at $60^{\circ} \mathrm{C}$. After repeating this procedure for several cycles, the specimens were pyrolyzed at $550^{\circ} \mathrm{C}$ for $4 \mathrm{~h}$ in air atmosphere with slow heating rate of $1^{\circ} \mathrm{C} / \mathrm{min}$ up to $300^{\circ} \mathrm{C}$ and a higher rate of $2^{\circ} \mathrm{C} / \mathrm{min}$ up to $550^{\circ} \mathrm{C}$. After naturally cooling to room temperature, a white product, $\mathrm{MoO}_{3}$ was obtained.

\subsection{Material characterization}

X-ray diffraction (XRD) was performed on a Bruker D8A25 X-Ray diffractometer, the X-ray beam was nickelfiltered $\mathrm{Cu} K \alpha(\lambda=0.15406 \mathrm{~nm})$ radiation operated at $40 \mathrm{kV}$ and $30 \mathrm{~mA}$; and the data were collected from $10^{\circ}$ to $80^{\circ}(2 \theta)$ at a scanning rate of $5 \% \mathrm{~min}$.

Thermal analysis (TG) was carried out on a NETZSCH STA 449 F5 equipment, operated under Air atmosphere. The samples were heated from room temperature up to $700^{\circ} \mathrm{C}$ at heating rates of $10^{\circ} \mathrm{C} / \mathrm{min}$.

The morphology of the samples was observed by JEOL JSM-5600LV SEM. EDX analysis was observed by Oxford Instruments.

\subsection{Battery preparation and performance test}

Electrochemical characterization of the $\mathrm{MoO}_{3}$ sample was carried out using three-electrode cells, in which a Graphite rod and an $\mathrm{Ag}-\mathrm{AgCl}$ electrode served as a counter and reference electrodes. The working electrodes were prepared by pressing a $1 \mathrm{~cm}^{2}$ thin film onto graphite paper. The sample electrode pellet was prepared by pressing the $8: 1: 1$ (in wt.) mixture of active materials, acetylene black and Polyvinylidene Fluoride(PVDF). The electrolyte was 1.0 $\mathrm{mol} / \mathrm{L} \mathrm{AlCl}_{3}$ solution purged with Nitrogen before use. Cyclic Voltammetry(CV) measurements were performed on a Ivium C16430 Electrochemical Analyst multichannel workstation manufactured by the Ivium Technologies with the cutoff voltage of $-0.6 / 0.2 \mathrm{~V}$ at room temperature.

\section{RESULTS AND DISCUSSION}

\subsection{Physical characterizations}

Figure 1 shows the TG/DTG curves of the raw material heated from room temperature to $700^{\circ} \mathrm{C}$ at a heating rate of $10^{\circ} \mathrm{C} / \mathrm{min}$. Three-step mass losses are observed on the TG curve, though the first peak is relatively weak. The first mass loss is due to the evaporation of adsorbed water. This transformation corresponds to the endothermic peak at $72^{\circ} \mathrm{C}$ as seen in the DTG curve. The release and burning of volatile matters corresponding to the complete decomposition of hemi-cellulose and cellulose, and the partial decomposition of lignin are responsible for the second peak between $200{ }^{\circ} \mathrm{C}$ and $300{ }^{\circ} \mathrm{C}$. The third step of mass loss is due to the decomposition of Ammonium Molybdate, which corresponds to the endothermic peak at $407^{\circ} \mathrm{C}$ seen in the DTG curve.

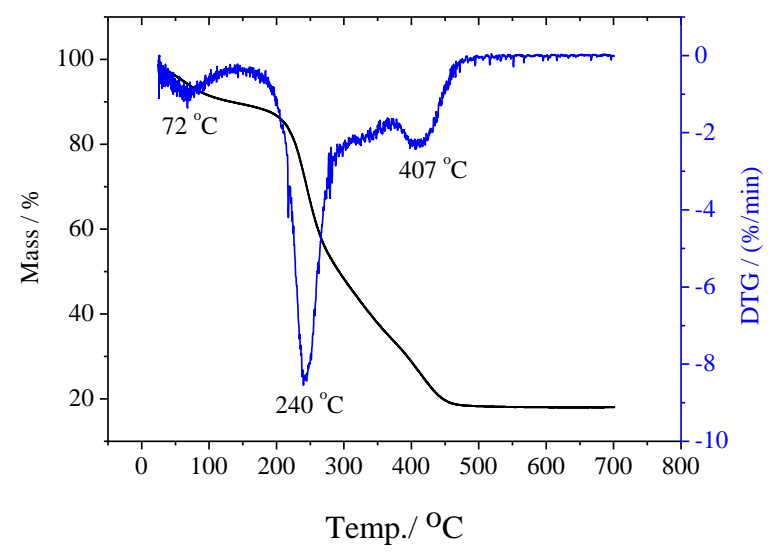

Figure 1 TG/DTG curves of the raw material

XRD measurement was first used to study the phase and lattice modification of the biotemplate $\mathrm{MoO}_{3}(\mathrm{II})$ and the $\mathrm{MoO}_{3}$ ( I ) sample prepared by solid state reaction. The corresponding X-ray powder diffraction patterns obtained at room temperature are presented in Figure 2. The diffraction peaks of the XRD pattern for both samples can be readily indexed to be Orthorhombic structures with space group Pbnm (62) and the cell parameters: $a=0.3963 \mathrm{~nm}$, $\mathrm{b}=1.3856 \mathrm{~nm}, \quad \mathrm{c}=0.36966 \mathrm{~nm}$ (International Centre for Diffraction Data (ICDD) No. 35-0609). The characteristic peaks at $2 \theta=12.7^{\circ}, 23.3^{\circ}, 25.7^{\circ}, 27.3^{\circ}, 33.7^{\circ}, 39.0^{\circ}$ and $49.2^{\circ}$ corresponded to the (020), (110), (040), (021), (111), (060) and (002) planes of $\mathrm{MoO}_{3}$, respectively. No peaks of any other phases were detected, indicating the high purity of both of $\mathrm{MoO}_{3}$ (I) and $\mathrm{MoO}_{3}$ ( II ) samples.

For the $\mathrm{MoO}_{3}$ (II) microrods, the stronger intensities of (020), (110), and (060) peaks than those for the bulk $\mathrm{MoO}_{3}(\mathrm{I})$ sample prepared by solid state reaction indicates the anisotropic growth of the nanostructure as well as the preferred orientation of the microrods on the substrate. Importantly, in comparison to the $\mathrm{MoO}_{3}(\mathrm{I})$, there is a shift of the (020) peak toward a lower diffraction angle for the $\mathrm{MoO}_{3}$ ( II ) microrods. This is direct evidence of an expanded $b$-plane interlayer distance, possibly due to the introduction of corn stalk Bio-template. According to Bragg's equation, the b-plane interlayer distance of the $\mathrm{MoO}_{3}(\mathrm{II})$ microrods increased from $1.387 \mathrm{~nm}$ to $1.425 \mathrm{~nm}$ with decreasing $2 \theta$ from 12.7619 to 12.4228 , which could be ascribed to the presence of biological templates. Notably, the expansion of the b-plane interlayer distance can accelerate the kinetic process of $\mathrm{Al}^{3+}$ intercalation/deintercalation and reduce the volume change during this process. 


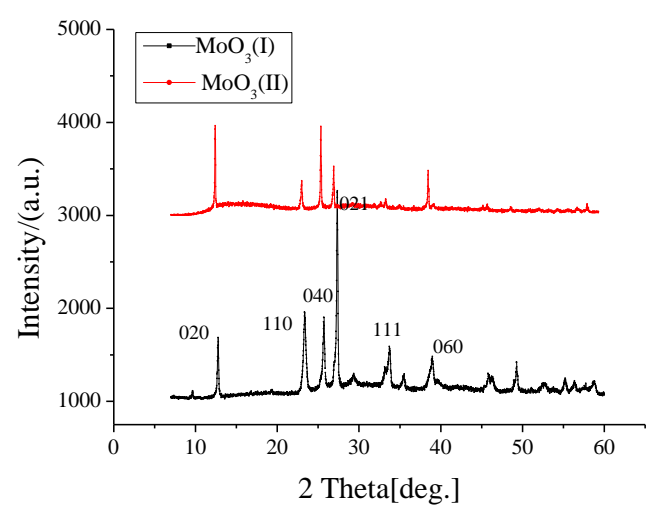

Figure 2. The XRD patterns of $\mathrm{MoO}_{3}$ (I) and $\mathrm{MoO}_{3}$ ( II ) samples

The morphology and microstructure of the products were observed by using SEM. Figures 3( I ) and ( II ) are the SEM images of $\mathrm{MoO}_{3}$ (I) and $\mathrm{MoO}_{3}$ ( II ), respectively. The results showed that the sample $\mathrm{MoO}_{3}$ (I) was formed as a massive structure with different particles agglomerated together, and most of the particles are approximately $1-4 \mu \mathrm{m}$. The sample $\mathrm{MoO}_{3}$ (II) showed a long segments with widths of 1-2 $\mu \mathrm{m}$ and lengths of $3-10 \mu \mathrm{m}$, and a rectanglelike cross section was clearly visible.

The elemental compositions of the $\mathrm{MoO}_{3}$ (II) were determined by Energy dispersive X-ray Spectroscopy (EDX). The sample contained only molybdenum and oxygen, as show in Figure 4. The corn stalk was decomposed completely when heated. The sample is a thin and yellow powdery crystal, and there is not any remaining carbonaceous material.
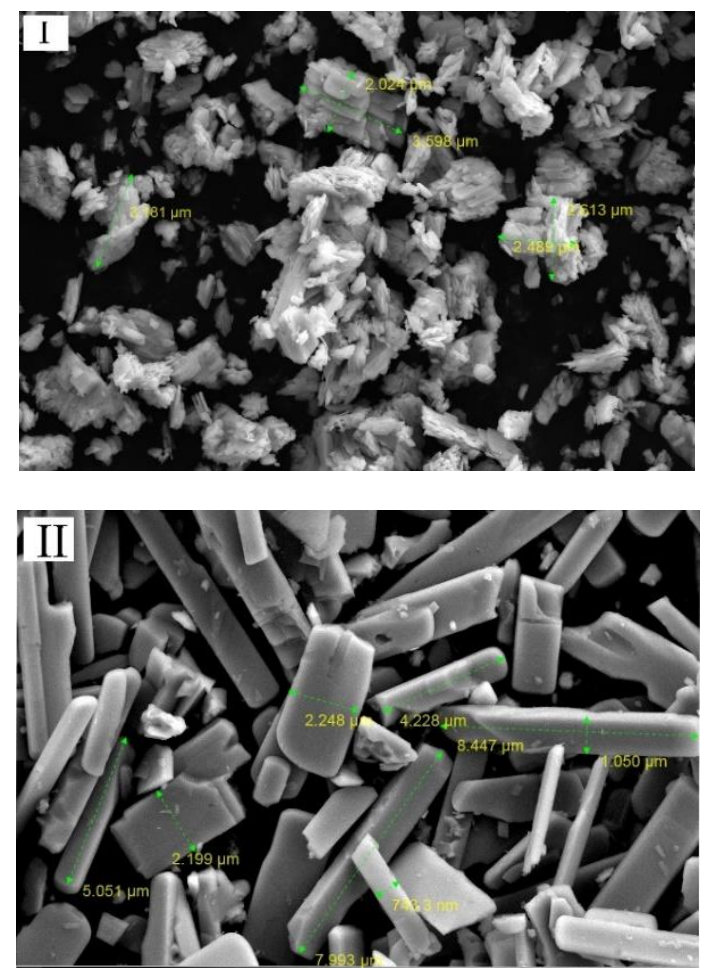

Figure 3. SEM images of $\mathrm{MoO}_{3}$ (I) and $\mathrm{MoO}_{3}$ (II ) samples
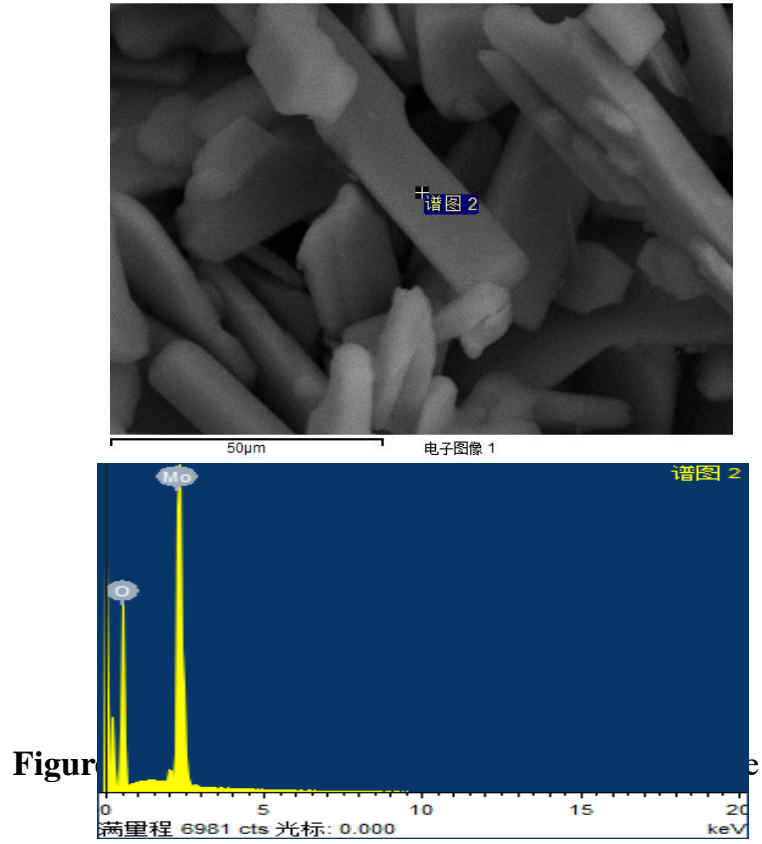

\subsection{Electrochemical performance}

Figure 5 and Figure 6 show the $\mathrm{CV}$ of $\mathrm{MoO}_{3}$ samples electrode in aqueous $\mathrm{AlCl}_{3}$ electrolyte in the potential range of $-0.6 \mathrm{~V}-0.2 \mathrm{~V}$ at a scan rate of $1 \mathrm{mV} / \mathrm{s}$. As shown in Figure 5, the main $\mathrm{CV}$ feature appears as three pairs of symmetric redox peaks at $0.01 /-0.14 \mathrm{~V},-0.06 /-0.19 \mathrm{~V}$, and $-0.39 /-0.53 \mathrm{~V}$, These results of $\mathrm{CV}$ suggest that the redox peaks result from the $\mathrm{Al}^{3+}$ ions. $\mathrm{MoO}_{3}$ can be used as the negative electrode material for aqueous aluminum ion batteries. Cyclic Voltammetry tests showed that the $\mathrm{MoO}_{3}$ ( II ) sample had a more obvious oxidation/reduction peak. The peak type was sharper and the peak current was higher. The discharge capacity of $\mathrm{MoO}_{3}$ (I) and $\mathrm{MoO}_{3}$ (II) samples were $74 \mathrm{mAh} / \mathrm{g}$ and $190 \mathrm{mAh} / \mathrm{g}$ after 5 cycles, respectively. Compared with $\mathrm{MoO}_{3}(\mathrm{I}), \quad \mathrm{MoO}_{3}(\mathrm{II})$ clearly showed higher discharge capacities and better cyclic ability.

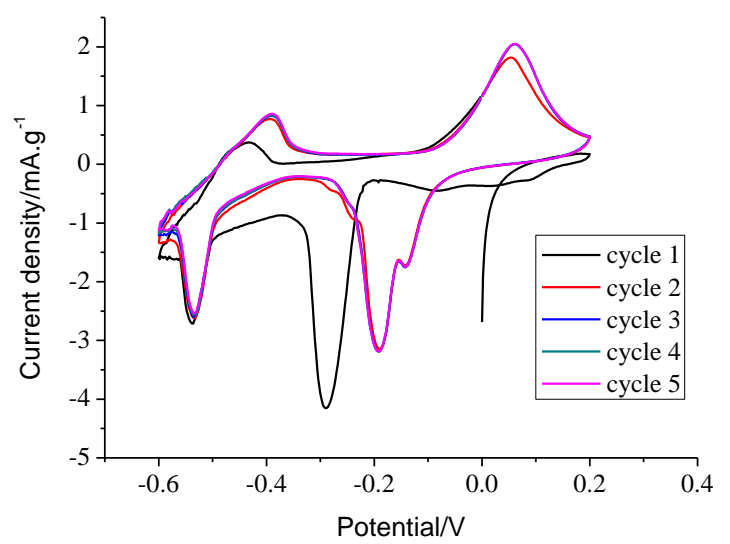

Figure 5. CV curves of measured $\mathrm{MoO}_{3}$ (I) at a scan rate of $1 \mathrm{mV} / \mathrm{s}$ 


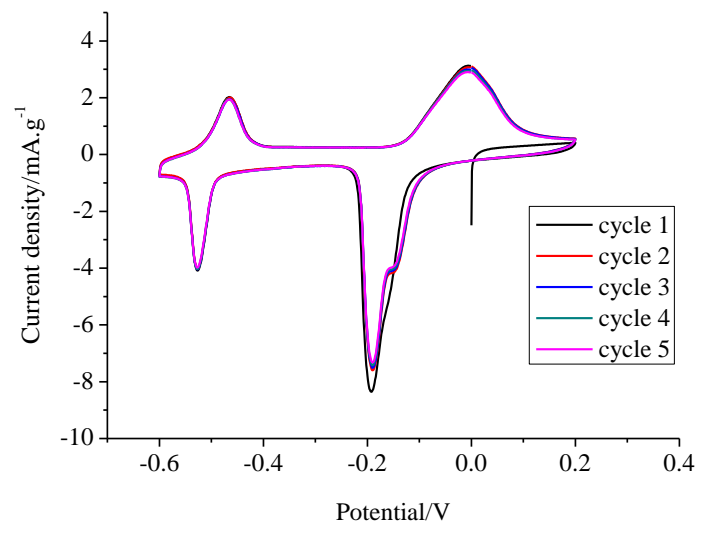

Figure 6. $\mathrm{CV}$ curves of measured $\mathrm{MoO}_{3}$ ( II ) at a scan rate of $1 \mathrm{mV} / \mathrm{s}$

The cyclic voltammogram (CV) were used to study the electrochemical performance of the samples in a $0.001 \mathrm{~mol} / \mathrm{L}$ and $0.01 \mathrm{~mol} / \mathrm{L} \mathrm{HCl}$ aqueous solution with a three-electrode cell. Figure 7 shows the $\mathrm{CV}$ curves of the asprepared electrodes show a little peaks at about $-0.37 \mathrm{~V}(\mathrm{pH}=3.0)$ and $-0.47 \mathrm{~V}(\mathrm{pH}=2.0)$. The peaks are obviously different from the peaks in $\mathrm{AlCl}_{3}$ aqueous solution. Experiment suggested that $\mathrm{Al}^{3+}$ (rather than $\mathrm{H}^{+}$) serves as the active ions and it is the insertion reaction between $\mathrm{MoO}_{3}$ and $\mathrm{Al}^{3+}$, which is consistent with the test results of Wang et al. ${ }^{[16]}$.

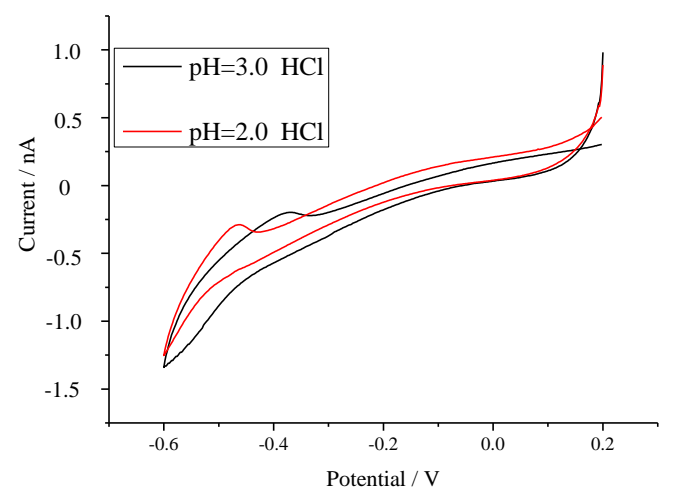

Figure 7. $\mathrm{CV}$ curves of measured $\mathrm{MoO}_{3}$ ( II ) in $\mathrm{HCl}$ aqueous solution

\section{CONCLUSIONS}

(1) The sample $\mathrm{MoO}_{3}$ materials prepared by biological template method showed a long segment with width of 1$2 \mu \mathrm{m}$ and lengths of $3-10 \mu \mathrm{m}$, and a rectanglelike cross section was clearly visible, exhibited distinct and reversible electrochemical intercalation behavior.

(2) Preliminary electrochemical data demonstrated that $\mathrm{MoO}_{3}$ ( II ) showed a higher peak current, a larger discharge capacity and a better recyclability compared with $\mathrm{MoO}_{3}$ ( I ).

(3) The discharge capacity of $\mathrm{MoO}_{3}$ ( II) is $190 \mathrm{mAh} / \mathrm{g}$ in the 5 th cycles at a current density of $1 \mathrm{mV} / \mathrm{s}$. An optimization of both the material structure and the electrolyte compatibility is necessary to increase the specific capacity and cycle performance.

\section{ACKNOWLEDGMENT}

Undergraduate University Teaching Reform Research Project of Shandong (M2018X015); Natural Science Foundation of Shandong Province(ZR2020MB134).

\section{REFERENCES}

[1] Dominique L., Tarascon J. M. (2015). Towards greener and more sustainable batteries for electrical energy $\begin{array}{llll}\text { storage. Nature } & \text { Chemistry, } 7 \text { : } 29 .\end{array}$ https://doi.org/10.1038/nchem.2085

[2] Zou J., Wu G., Jiang W., Bao C.W., Zou J.Y. (2020). Effects of $\mathrm{TiO}_{2}$ Nanotube Size on the Performance of Li-Ion Battery with $\mathrm{TiO}_{2}$ Nanotube as Anode Material. Journal of New Materials for Electrochemical Systems, 23 , $4: 280-284$ https://doi.org/10.14447/jnmes.v23i4.a10

[3] Gao Y., Yang H., Wang X.R., Bai Y., Zhu N., Guo S.N., Suo L.M., Li H., Xu H.J., Wu C. (2020). The compensation effect mechanism of $\mathrm{Fe}-\mathrm{Ni}$ mixed Prussian blue analogues in aqueous rechargeable aluminum-ion batteries. Chem Sus Chem, 13, 732-740. https:// doi.org//10.1002/cssc.201903067

[4] Nandi S., Lahan H., Das S. K. (2020). A proof of concept for low-cost rechargeable aqueous aluminumion battery. Bulletin of Materials Science, 43(1), 26. https://doi.org/10.1007/s12034-019-1988-9

[5] Zhang H.Y., Cao D.X., Bai X. (2019). High rate performance of aqueous magnesium-ion batteries based on the $\delta-\mathrm{MnO}_{2} @$ carbon molecular sieves composite as the cathode and nanowire $\mathrm{VO}_{2}$ as the anode. Journal of Power Sources, 444: 227299- 227305. https://doi.org/10.1016/j.jpowsour.2019.227299

[6] Mai L.Q., Hu B., Chen W., Qi Y.Y., Lao C.S., Yang R.S., Wang Z.L. (2007). Lithiated $\mathrm{MoO}_{3}$ Nanobelts with Greatly Improved Performance for Lithium Batteries. Advanced Materials, 19: 3712-3716. https://doi.org/10.1002/adma.200700883

[7] Li T.Q., Beidaghi M.J., Xiao X., Huang L., Hu Z.M., Sun W.M., Chen X., Gogotsi Y., Zhou J. (2016). Ethanol reduced molybdenum trioxide for Li-ion capacitors. Nano Energy, 26: 100-107. https://doi.org/10.1016/j.nanoen.2016.05.004

[8] Lahan H., Das S. K. (2019). $\mathrm{Al}^{3+}$ ion intercalation in $\mathrm{MoO}_{3}$ for aqueous aluminum-ion battery. J Power Sources, 413: 134-138. https://doi.org/10.1016/j.jpowsour.2018.12.032

[9] Lahan H., Das S. K. (2019). Graphene and diglyme assisted improved $\mathrm{Al}^{3+}$ ion storage in $\mathrm{MoO}_{3}$ nanorod: Steps for high-performance aqueous aluminum-ion battery. Ionics, 25(7): 3493-3498. https://doi.org/10.1007/s11581-019-03058-6

[10] Liu C., Wu F., Su Q.Q., Qian W.P. (2019). Template Preparation and Application in Biological Detection of Porous Noble Metal Nanostructures. Progress in Chemistry, https://doi.org/10.7536/PC190323
8:1396-1405. 


\section{Jianzhi Sun et al. / J. New Mat. Electrochem. Systems}

[11] Huang Y.T., Ying Z.P., Zheng J.X., Zhuang S.G., Liu L., Feng W. (2018). Hierarchical Porous $\mathrm{ZnO}$ Nanomaterial Synthesized with Corn Straw as Biological Templates and Its Photocatalytic Performance. Chemical Journal of Chinese Universities, 39: 2031-2038. https://doi.org/10.7503/cjcu20180110

[12] Liu S., Hu J.J., Yan N.F., Pan G.L., Li G.R., Gao X.P. (2012). Aluminum storage behavior of anatase $\mathrm{TiO}_{2}$ nanotube arrays in aqueous solution for aluminum ion batteries. Energy \& Environmental Science, 5: 97439746. https://doi.org/10.1039/D0EE03801F

[13] Reed L.D., Menke E. (2012). The Roles of $\mathrm{V}_{2} \mathrm{O}_{5}$ and Stainless Steel in Rechargeable Al-Ion Batteries. Journal of the Electrochemical Society, 160: A915-917. https://doi.org/10.1149/2.114306jes

[14] González J.R., Nacimiento F., Cabello M., Alcántara R., Lavela P., Tirado J.L. (2016). Reversible intercalation of aluminium into vanadium pentoxide xerogel for aqueous rechargeable batteries, Rsc Advances, 6: 62157-62164. https://doi.org/10.1039/C6RA11030D
[15] Nacimiento F., Cabello M., Alcántara R., Lavela P., Tirado J.L. (2018). NASICON-type $\mathrm{Na}_{3} \mathrm{~V}_{2}\left(\mathrm{PO}_{4}\right)_{3}$ as a new positive electrode material for rechargeable aluminium battery. Electrochimica Acta, 260: 798-804. https://doi.org/10.1016/j.electacta.2017.12.040

[16] Wang F.X., Liu Z.C., Wang X.W., Yuan X.H., Wu X.W., Zhu Y.S., Fu L.J., Wu Y.P. (2016). A conductive polymer coated $\mathrm{MoO}_{3}$ anode enables an Al-ion capacitor with high performance, Journal of Materials Chemistry A, 4: 5115-5123. https://doi.org/10.1039/C6TA01398H

[17] Ramachandran R., Xuan W.L., Zhao C.H., Leng X.H., Sun D.Z., Luo D., Wang F. (2018). Enhanced electrochemical properties of cerium metal-organic framework based composite electrodes for highperformance supercapacitor application, RSC Advances, 7: 3462-3469. https://doi.org/10.1039/C7RA12789H 